Research article

$\underline{\text { urn:1sid:zoobank.org:pub:603DDB0C-081B-4002-8001-A3386D53CAB0 }}$

\title{
The genus Brachypsectra LeConte, 1874 (Coleoptera: Brachypsectridae) in the Palaearctic Region
}

\author{
Ivana PETRZELKOVA ${ }^{1}$, Christodoulos MAKRIS ${ }^{2}$ \& Robin KUNDRATA ${ }^{3, *}$ \\ ${ }^{1,3}$ Department of Zoology, Faculty of Science, Palacky University, 17. listopadu 50, \\ 77146 Olomouc, Czech Republic. \\ ${ }^{2}$ Ethnikis Antistaseous 21, 3022 Lemesos, Cyprus. \\ *Corresponding author: robin.kundrata@upol.cz \\ ${ }^{1}$ Email: ivana.petrzelkova01@upol.cz \\ ${ }^{2}$ Email: r.c.makris@cytanet.com.cy
}

${ }^{1}$ urn:1sid:zoobank.org:author:AAC053E2-B262-4612-8FDF-6F66E27758D4

${ }^{2}$ urn:1sid:zoobank.org:author:30FE321F-DE37-4380-A624-8DC258F8FC45

3urn:Isid:zoobank.org:author:98C7998C-7752-47A5-91FE-9A05D306FB92

\begin{abstract}
We summarize all information regarding the genus Brachypsectra (Coleoptera: Brachypsectridae) in the Palaearctic Region. New material of B. kadleci Hájek, 2010 is reported from western and southern Iran and its intraspecific variability in coloration and morphology is described and figured. Brachypsectra jaechi sp. nov. from southern Turkey is described from males, and an unassociated Brachypsectra species from Cyprus is reported, including the descriptions of its female and larva. These findings are the first records of this genus as well as of the family Brachypsectridae for Turkey and Cyprus. Additionally, a diagnostic key to the adult males and larvae of all Brachypsectra species is updated.
\end{abstract}

Keywords. Cyprus, distribution, Elateroidea, Iran, Turkey.

Petrzelkova I., Makris C. \& Kundrata R. 2016. The genus Brachypsectra LeConte, 1874 (Coleoptera: Brachypsectridae) in the Palaearctic Region. European Journal of Taxonomy 276: 1-14. http://dx.doi.org/10.5852/ ejt.2017.276

\section{Introduction}

The genus Brachypsectra LeConte, 1874, the sole member of the family Brachypsectridae, was originally placed in the dascilloid Rhipiceridae and later in the Dascillidae (LeConte 1874; Horn 1881, respectively). However, subsequent workers recognized this group as an independent family with close affinities to present-day Elateroidea (e.g., Blair 1930; Crowson 1973; Lawrence \& Newton 1995), which has recently been confirmed by both morphological and molecular-based studies (Lawrence et al. 2011; McKenna et al. 2015). 
Previously, only five formally described extant species were accommodated in Brachypsectra. LeConte (1874) described B. fulva LeConte, 1874 from North America and Blair (1930) added B. fuscula Blair, 1930 and B. lampyroides Blair, 1930 from the Oriental Region. Later authors focused mainly on the American B. fulva (e.g., Neck 1993; Fleenor \& Taber 1999, 2000; Young 2002) and only Woodruff (2004) described B. vivafosile Woodruff, 2004 from the Dominican Republic. Costa et al. (2006) described the larva of an unnamed species from Australia, which had been mentioned earlier by Lawrence (1991) and Lawrence \& Britton (1991). Information on the Oriental species had remained scarce until Klausnitzer (2009) studied several larvae from Goa, India, which are probably conspecific with B. lampyroides. Hájek (2010) described the first Brachypsectra species in the Palaearctic Region from a single specimen (i.e., B. kadleci Hájek, 2010) and hypothesized that findings of more undescribed species of this genus could be expected in the future. Indeed, the possibility to study material from major European museums together with fresh material collected by the authors has led to the discovery of several distinct Brachypsectra populations in Iran, Turkey and Cyprus.

In this study, we summarize all information regarding the genus Brachypsectra in the Palaearctic Region. New material of $B$. kadleci from different localities in Iran is reported and its intraspecific variability is described and figured. Brachypsectra jaechi sp. nov. from Turkey is described from males and an unassociated Brachypsectra species from Cyprus is reported, including the description of its female and larva. Additionally, a diagnostic key to the adult males and larvae of all Brachypsectra species is updated.

\section{Material and methods}

We studied the larval and adult male morphology of specimens of Brachypsectra. The genitalia were dissected, kept in hot $10 \% \mathrm{KOH}$ for approximately five minutes, transferred to glycerol and subsequently photographed by a digital camera attached to a stereoscopic microscope. Measurements were taken with an ocular scale bar on a microscope as follows: body length - measured from the fore margin of the head to the apex of the elytra; body width - at the widest part; pronotal length - at midline; pronotal width - between the posterior angles; minimum interocular distance - in anterodorsal view; maximum eye diameter - in lateral view.

The morphological terminology and generic definition of Brachypsectra used herein follows Costa et al. $(2006,2010)$ and Hájek (2010).

\section{Institutional abbreviations}

The examined material is deposited in the following collections, listed here by their abbreviated names:

NMPC $=$ Národní Muzeum, Prague, Czech Republic

NHMW $=$ Naturhistorisches Museum, Vienna, Austria

$\mathrm{HNHM}=$ Hungarian Natural History Museum, Budapest, Hungary

PCCM $=$ Collection of Christodoulos Makris, Lemesos, Cyprus

PCRK $=$ Collection of Robin Kundrata, Olomouc, Czech Republic 
PETRZELKOVA I. et al., The genus Brachypsectra in the Palaearctic Region.

Table 1. List of species in the genus Brachypsectra LeConte. * = known only from amber fossils.

\begin{tabular}{cc}
\hline Species & Distribution \\
\hline Brachypsectra fulva LeConte, 1874 & Mexico, USA \\
Brachypsectra fuscula Blair, 1930 & Singapore \\
Brachypsectra jaechi sp. nov. & Turkey \\
Brachypsectra kadleci Hájek, 2010 & Iran \\
Brachypsectra lampyroides Blair, 1930 & India \\
Brachypsectra moronei Branham in Costa et al., 2006* & Dominican Republic (amber) \\
Brachypsectra vivafosile Woodruff, 2004 & Dominican Republic \\
Brachypsectra sp. 1 (Costa et al. 2006) & Australia \\
Brachypsectra sp. 2 (Klausnitzer 2009)* & Baltic amber \\
Brachypsectra sp. 3 (this paper) & Cyprus \\
\hline
\end{tabular}

\title{
Results
}

\author{
Class Hexapoda Blainville, 1816 \\ Order Coleoptera Linnaeus, 1758 \\ Suborder Polyphaga Emery, 1886 \\ Series Elateriformia Crowson, 1960 \\ Superfamily Elateroidea Leach, 1815 \\ Family Brachypsectridae Horn, 1881 \\ Genus Brachypsectra LeConte, 1874
}

Brachypsectra LeConte, 1874: 55. Type species: Brachypsectra fulva LeConte, 1874: 56.

\section{Remarks}

For a detailed generic description and species overview see Costa et al. $(2006,2010)$. Distributions of the currently recognized species are given in Table 1 . The present study concentrates on the species of Brachypsectra in the Palaearctic Region.

Brachypsectra kadleci Hájek, 2010

Figs 1A-D; 2A, D-E

Brachypsectra kadleci Hájek, 2010: 30.

\section{Diagnosis}

\section{Males}

Body 4.8-5.9 mm long, 2.3-2.5 times as long as wide. Body surface testaceous, with elytra either darker, reddish-brown to dark brown (specimens from western Iran, including the holotype; Fig. 1A-B) or yellowish-testaceous to testaceous (populations from southern Iran; Fig. 1C-D), legs yellow to yellowish-testaceous. Eyes large, minimum interocular distance $0.95-1.05$ times maximum eye diameter. Pronotum 1.8-1.9 times wider than long, subtrapezoidal, widest posteriorly, width between posterior angles 1.5-1.7 times width between anterior angles; lateral sides convex, strongly converging anteriorly and moderately strongly diverging posteriorly; posterior angles produced posteriorly and slightly to moderately laterally, apically truncated, with short distinct posterior carina, well separated from lateral carina in dorsal view (Figs 1A-D, 2A). Scutellum subtrapezoidal, with apex narrowly 
rounded. Aedeagus with median lobe more or less gradually converging apically, more distinctly attenuating subapically in specimens from Lorestan (including the holotype); parameres slightly constricted subapically, with distinct subapical, rounded lateral projection and projected rounded apex. Phallobase short, narrowed and slightly emarginated basally, almost sub-parallel apically (Fig. 2D-E). Female unknown. For the differences between B. kadleci and B. jaechi sp. nov. see the Diagnosis section under the latter species.

\section{Material examined}

\section{Holotype}

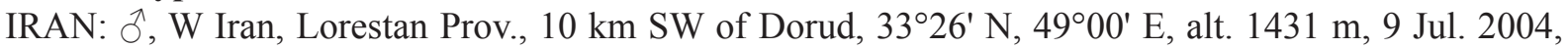
S. Kadlec leg., ex coll. S. Kadlec (NMPC).
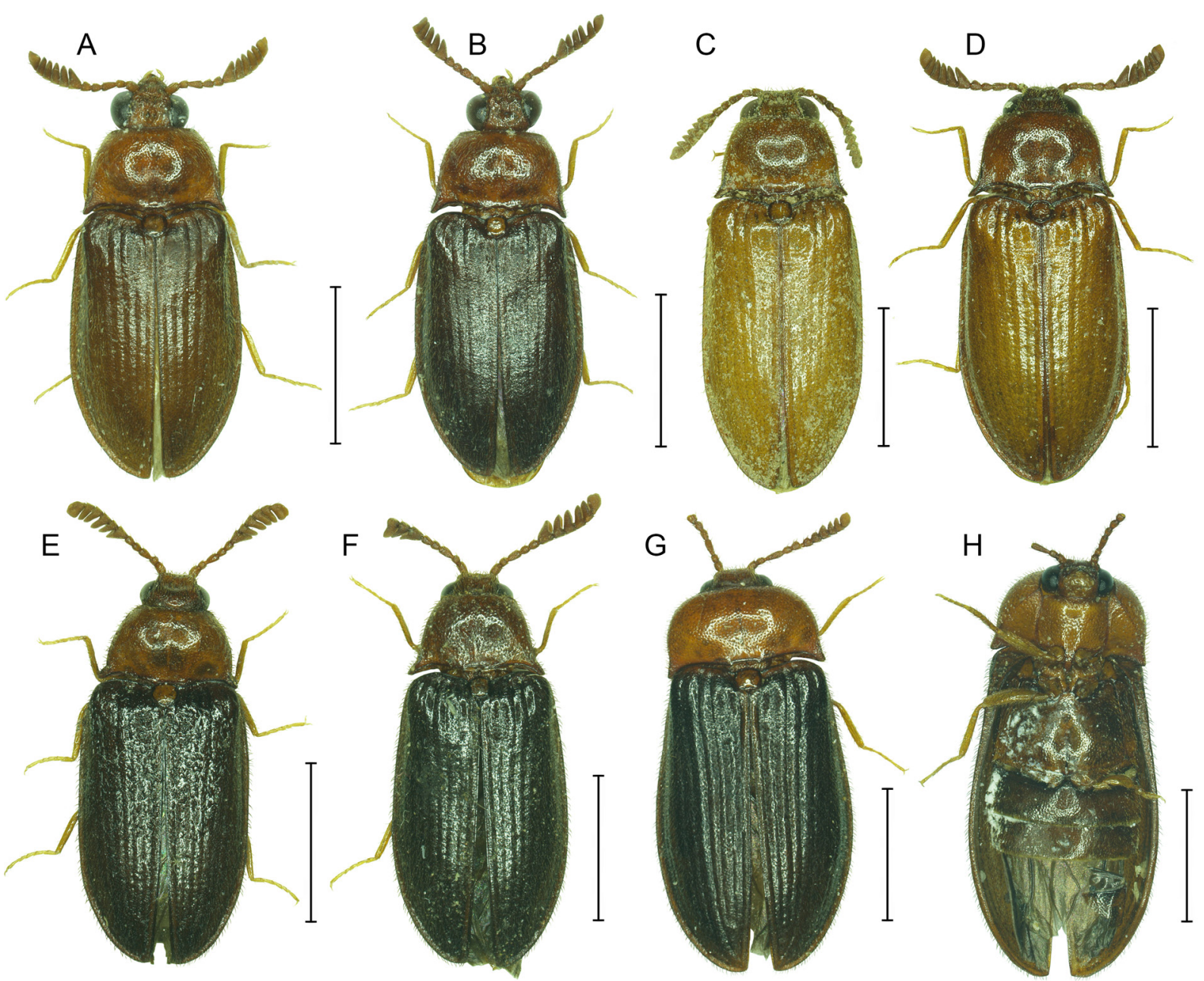

Fig. 1. Habitus of Brachypsectra spp. in the Palaearctic Region. A-D. $\hat{o}^{\widehat{\partial}}$ of $B$. kadleci Hájek, 2010, Iran. A. Holotype, Lorestan. B. Non-type specimen from Lorestan. C. Specimen from Bezan. D. Specimen from Minab. - E-F. $\overbrace{}^{\lambda}$ of B. jaechi sp. nov., Turkey, Kemer. E. Holotype. F. Paratype. $-\mathbf{G}-\mathbf{H}$. $q$ of Brachypsectra sp. from Cyprus. G. Dorsal view. H. Ventral view. Scale bars $=2 \mathrm{~mm}$. 

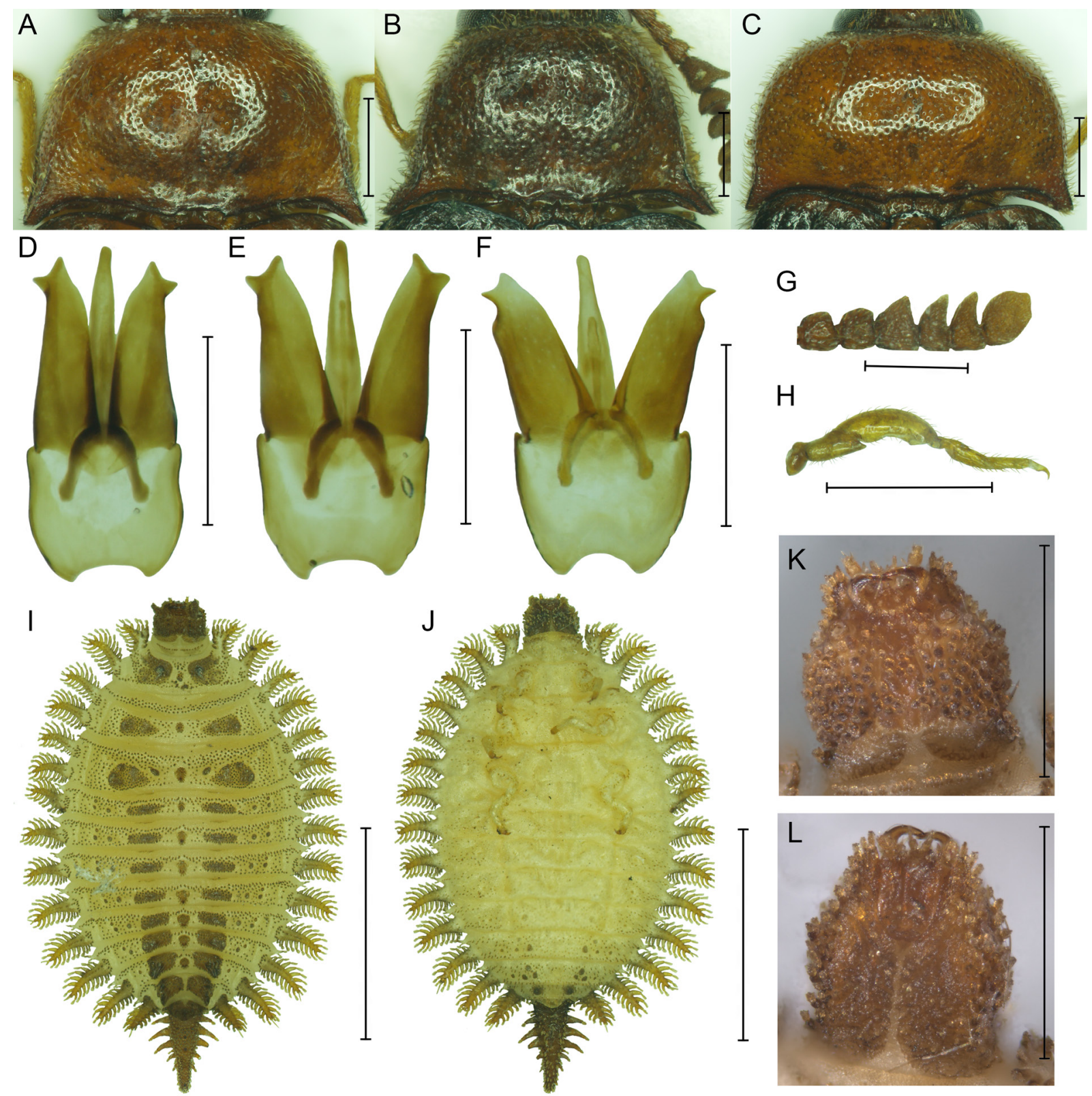

Fig. 2. A-C. Pronotum of Brachypsectra spp. A. đ of B. kadleci Hájek, 2010, holotype. B. ô of B. jaechi sp. nov., paratype. C. $q$ of Brachypsectra sp. from Cyprus. - D-F. Aedeagus of Brachypsectra spp. D. B. kadleci, Iran, Lorestan. E. B. kadleci, Iran, Geno. F. B. jaechi sp. nov., Turkey, Kemer. G. + , apical part of antenna of Brachypsectra sp. from Cyprus. - H. + , apparently underdeveloped metathoracic leg of Brachypsectra sp. from Cyprus. - I-J. Habitus of Brachypsectra sp. from Cyprus, larva. I. Dorsal view. J. Ventral view. - K-L. Head of Brachypsectra sp. from Cyprus, larva (antennae removed). K. Dorsal view. L. Ventral view. Scale bars: A-H, K-L $=0.5 \mathrm{~mm}$; I-J $=2 \mathrm{~mm}$. 


\section{Other material examined}

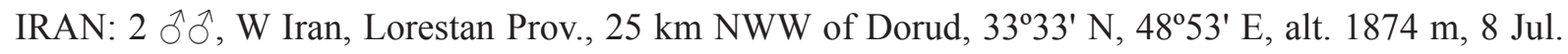

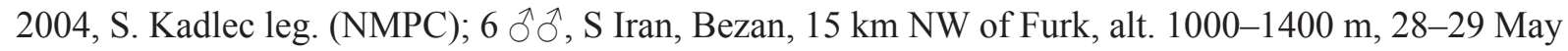
1973, Loc. no. 218, Exped. Nat. Mus. Praha [see Hoberlandt 1981] (NMPC); 2 $\widehat{\jmath}$, S Iran, alt. 400 m, 6 km W of Geno, 7-9 May 1977, Loc. no. 323, Exped. Nat. Mus. Praha [see Hoberlandt 1983] (NMPC); ऽ, S Iran, $25 \mathrm{~km}$ S of Minab, 4 May 1974, Lichtlang (27), Exped. Mus. Vindob, Pretzmann leg. (NMPC);

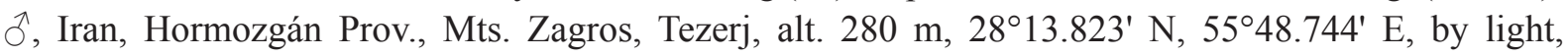
1-2 May 2008, T. Hácz, K. Székely and K. Vig. leg., T. Németh det., 2013 (HNHM).

\section{Distribution}

This species is known from western and southern Iran (Fig. 3).

\section{Remarks}

There is intraspecific variability in populations of $B$. kadleci. Specimens from the type locality (Lorestan, western Iran; Fig. 3) are distinctly bicolored with darker elytra (Fig. 1A-B) and have the median lobe of the aedeagus almost sub-parallel, more distinctly attenuating subapically (Fig. 2D). Specimens collected in southern Iran (Fig. 3) are almost uniformly yellowish-testaceous to testaceous (Fig. 1C-D), with the median lobe of the aedeagus more gradually narrowed towards the apex (Fig. 2E). Taking into consideration the gradation in elytral coloration (from yellowish-testaceous through testaceous and reddish-brown to dark brown; Fig. 1A-D), slight differences in the shape of the median lobe and the rarity of the specimens available for study, we refrain here from making any taxonomic conclusions and consider all specimens from Iran conspecific. Brachypsectra fulva from North America and Brachypsectra

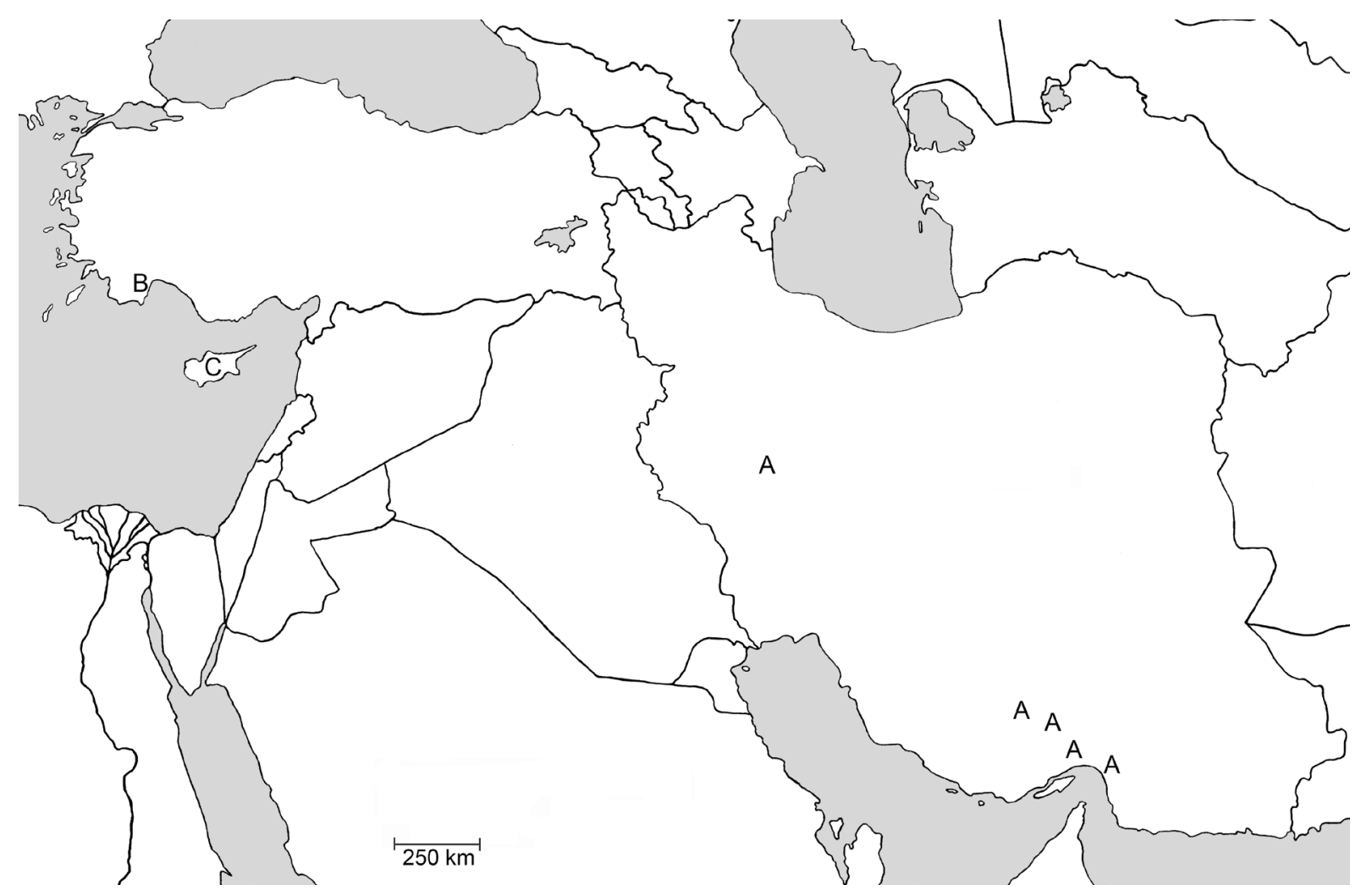

Fig. 3. Distribution of Brachypsectra in the Palaearctic Region. A=B. kadleci Hájek, 2010; B = B. jaechi sp. nov.; $\mathrm{C}=$ Brachypsectra sp. from Cyprus. 
PETRZELKOVA I. et al., The genus Brachypsectra in the Palaearctic Region.

sp. from Australia have even wider distribution ranges (ca $2000 \mathrm{~km}$ ) than B. kadleci (ca $1000 \mathrm{~km})$, and B. fulva exhibits much wider geographic variation in size and external morphology (Costa et al. 2006). More material from the different localities in Iran, as well as DNA-based studies, might help to resolve the taxonomic status of the different Iranian populations considered here conservatively as $B$. kadleci.

\section{Brachypsectra jaechi sp. nov. urn:1sid:zoobank.org:act:ED78F0DE-63CF-4674-8CD6-39523A44E2CC}

Figs 1E-F; 2B, F

\section{Diagnosis}

This species is morphologically similar to Brachypsectra kadleci (Fig. 1A-F), but differs in having smaller eyes (minimum interocular distance 1.40-1.45 times maximum eye diameter in B. jaechi sp. nov., 0.95-1.05 times in $B$. kadleci), pronotal lateral sides more strongly diverging posteriorly, with posterior angles more distinctly produced laterally and posterior carina far from lateral carina, closer to posterior margin (Fig. 2A-B), width between posterior angles 1.9 times width between anterior angles (1.5-1.7 times in B. kadleci), scutellum more broadly rounded posteriorly (narrowly rounded in B. kadleci), phallobase more deeply emarginated basally, gradually diverging apically (more angulate, almost subparallel-sided apically in B. kadleci), and parameres wider, distinctly constricted subapically, with subapical lateral projection subacute (slightly constricted subapically, with subapical lateral projection rounded in B. kadleci; Fig. 2D-F).

\section{Etymology}

The specific epithet is a patronym in honor of Manfred A. Jäch (NHMW).

\section{Type material}

\section{Holotype}

TURKEY: §̊, Kemer, Antalya Prov., 3-15 Jul. 1989, H. Schmid leg. (NHMW).

\section{Paratype}

TURKEY: $\widehat{\partial}$, same data as for holotype (NHMW).

\section{Type locality}

Turkey, Antalya Prov., Kemer.

\section{Description}

\section{Male (holotype)}

Body. $5.6 \mathrm{~mm}$ long, 2.3 times as long as wide, elongate oblong, dorsoventrally flattened. Body surface testaceous to reddish brown, ventral parts of thorax darker, elytra dark brown, legs yellowish-testaceous; body covered with yellow pubescence (Fig. 1E).

HEAD. Including eyes 0.5 times as wide as pronotum; eyes medium-sized, protuberant; minimum interocular distance 1.45 times maximum eye diameter; frons depressed medially; head covered with shallow, irregularly distributed punctures and short, semi-erect to erect pubescence. Antenna 11-segmented; scape elongate; pedicel short, subquadrate; antennomere 3 elongate, about two times longer than wide; antennomeres 4 and 5 simple, subequal, slightly longer than wide; antennomeres 6-10 expanded on one side to form (with apical antennomere) a pectinate club; apical antennomere expanded, with additional trapezoidal broadening apically (Fig. 1E). 
Pronotum. Transverse, 1.9 times as wide as long, subtrapezoidal, widest posteriorly, width between posterior angles 1.9 times width between anterior angles; anterior margin almost straight; lateral sides convex, strongly converging anteriorly and diverging posteriorly, with distinct lateral carina concealed anteriorly in dorsal view; posterior margin trisinuate. Anterior angles obtuse, posterior angles produced posterolaterally, apically truncated, with short, distinct posterior carina, well separated from lateral carina in dorsal view (Fig. 2B). Disc convex, with very shallow longitudinal medial furrow, covered with sparse subcircular punctures and short, semi-erect pubescence. Prosternum slightly convex, including prosternal process 1.2 times as long as wide, sparsely covered with coarse punctures; chinpiece very short; prosternal process subparallel-sided, curved, slightly converging apically, with apex broadly rounded. Scutellum subtrapezoidal, slightly wider than long, lateral edges slightly rounded, apex broadly rounded. Metaventrite finely and sparsely punctate. Elytra subparallel-sided, slightly widened at posterior third, about $3 / 4$ of body length, 1.7 times as long as combined width, 4.0 times as long as pronotum, with distinct humeral bulge and widened lateral margins; disc dorsoventrally flattened, very weakly striate, covered with fine punctures and short, semi-erect pubescence. Legs moderately long, slender, slightly compressed; tarsomeres 1-4 gradually shortened, tarsomere 4 minute, apical tarsomere narrow, longest; claws simple.

Abdominal ventrites. Flattened, finely and moderately densely punctate; ventrites $1-4$ subequal in length, ventrite 5 broadly rounded posteriorly. Aedeagus trilobate; median lobe longer than paramera, gradually narrowed towards apex, slightly constricted subapically, rounded apically, with moderately long basal struts, u-shaped, slightly converging anteriorly. Parameres robust, longer than phallobase, moderately wide, distinctly constricted subapically, with distinct subapical subacute lateral projection and projected rounded apex. Phallobase short, wider than long, narrowed and moderately deeply emarginated basally, gradually diverging apically (Fig. 2F).

\section{Female and immature stages}

Unknown.

\section{Intraspecific variability}

The second known male specimen (Fig. 1F) is $5.0 \mathrm{~mm}$ long, with the body 2.4 times as long as wide, pronotum 2.0 times as wide as long, and the minimum distance between eyes 1.40 times longer than the eye diameter.

\section{Distribution}

This species is known only from Kemer in Antalya Province, southern Turkey (Fig. 3).

\section{Brachypsectra sp.}

Figs $1 \mathrm{G}-\mathrm{H} ; 2 \mathrm{C}$, G-L

\section{Material examined}

CYPRUS: + , Pafos, Vretsia, alt. 600 m, dead under bark of Quercus infectoria, 2 Aug. 2011, Ch. Makris leg. (PCCM); larva, Pafos, Vretsia, under bark of Quercus infectoria, 3 Jul. 2015, Kundrata and Petrzelkova leg. (PCRK).

\section{Description}

\section{Female}

BoDy. $6.0 \mathrm{~mm}$ long, 2.2 times as long as wide, elongate oblong, dorsoventrally flattened. Body surface testaceous to reddish brown, metaventrite and abdomen darker, elytra dark brown (margins lighter), legs yellowish-testaceous; body covered with yellow pubescence (Fig. 1G-H). 
PETRZELKOVA I. et al., The genus Brachypsectra in the Palaearctic Region.

HeAd. Eyes medium-sized; minimum interocular distance 1.39 times maximum eye diameter; frons shallowly depressed medially. Antenna with antennomere 3 elongate, more than 2.5 times as long as wide; antennomeres 4 and 5 simple, subequal, slightly longer than wide; antennomeres 6-7 short, subquadrate, antennomeres 8-9 expanded on one side to form (with apical antennomere) a pectinate club; apical antennomere expanded, with additional trapezoidal broadening apically (Fig. 2G).

Pronotum. Transverse, 2.0 times as wide as long, widest posteriorly, width between posterior angles 2.0 times width between anterior angles; lateral sides convex, strongly converging anteriorly and only slightly diverging posteriorly, with distinct lateral carina almost completely concealed in dorsal view. Posterior angles relatively wide, produced posteriorly, apically truncated, with short distinct posterior carina, close to lateral carina in dorsal view (Fig. 2C). Disc strongly convex, posteriorly with shallow longitudinal medial furrow. Prosternum including prosternal process 1.1 times as long as wide, sparsely and coarsely punctured; prosternal process subparallel-sided, considerably curved, converging apically, with apex subacute (Fig. 1H). Scutellum subtrapezoidal, slightly wider than long, apex very slightly emarginate. Elytra gradually widened at posterior third, 4.2 times as long as pronotum; disc clearly striate, covered with moderately fine punctures. Only three legs present; pro- and mesothoracic legs well-developed, moderately long, with tarsomeres 1-4 gradually shortened, tarsomere 4 minute, and apical tarsomere narrow, longest; metathoracic leg minute (anomaly?), only trochanter well-developed, remaining parts reduced, tarsomeres fused together, only one simple claw present (Figs 1H, 2H).

Abdominal Ventrites. Finely and moderately densely punctate; only first two ventrites present (Fig. 1H). Genitalia missing.

\section{Larva}

Body. $4.6 \mathrm{~mm}$ long, $2.2 \mathrm{~mm}$ wide (without lateral lobes). Body broadly ovate, strongly flattened, covered with modified scale-like setae; thoracic segments and abdominal segments I-VIII with lateral lobes bearing elongate setiferous lobules (Fig. 2I-J). Body yellow, except dark brown pigmented head, abdominal segment IX and pigmented areas, median projections and small setiferous tubercles on dorsal surfaces, and apical parts of legs.

HEAD. Prognathous, subtrapezoidal, slightly elevated, slightly wider than long, narrower than prothorax, with large stemma on each side (Fig. 2K-L). Epicranial stem very short, frontal arms slightly lyriform. Antennae less than half of head width; antennomere 1 short, about as long as wide, antennomere 2 enlarged, 2 times as wide as long, widest medially, sparsely covered with modified scale-like setae, shorter in middle, longer and arranged in rows laterally; antennomere 3 highly reduced; sensorium conical. Labrum free, transverse, small, setose apically. Mandibles falcate, moderately stout, considerably curved. Maxillary palpi four-segmented, with segment 2 longest. Labial palpi two-segmented, basal segment about as long as wide, apical segment about as long as basal one, elongate, narrow. Gular sutures present, gula very narrow. Cervical region membranous, dorsally with transverse row of setiferous tubercles, disconnected medially.

THORACIC TERGA. Transverse, sparsely covered with setiferous tubercles, each tergum with pair of laterotergal lobes on each side; lobes equal in length, narrow, lined with narrow, setiferous lobules. Each tergum with median oval projection (largest at metatergum) and pair of irregularly shaped pigment patches (located more posteriorly at meso- and metatergum), consisting of several smaller slightly protruding pigmented areas. Mesotergum transversely divided into anterior very narrow plate covered uniformly with setiferous tubercles and posterior plate bearing also median projection and pigment patches. Thoracic sterna unpigmented, almost smooth, clothed very sparsely with short setae. Legs well-developed, prothoracic leg and mesothoracic spiracle not close together; spiracles located on mesosternal anterolateral transverse sclerites. 
ABdominal terga. Terga I-VIII transverse, covered with setiferous tubercles and with median projection (missing from tergum VIII) and pair of pigment patches similarly as on thoracic terga (smaller and transverse on anterior segments, larger and plate-like on posterior segments), with pair of laterotergal lobes on each side; posterior lobe similar to thoracic ones, anterior lobe minute, bearing 1-3 setiferous lobules. Lateral parts of abdominal tergites bearing spiracles, with two small, rounded pigment patches behind spiracles on terga I-V, with one patch on tergum VI, remaining terga without such patches. Tergum IX forming long, well-sclerotized, tail-like plate covered with setiferous tubercles, with several lateral branches of different lengths. Abdominal sterna I-V without well-developed pigment patches, sterna VI-VII with four pigment patches of different sizes on each side; sternum VIII with pair of larger patches.

\section{Remarks}

The only adult specimen of Brachypsectra known from Cyprus is a dead, partly damaged female (Fig. 1G-H) found by Ch. Makris in August 2011 under oak bark in Vretsia, Paphos (Fig. 4A-B). Unfortunately, the last three abdominal ventrites are missing in this specimen (Fig. 1H), so we are not able to study the genitalia. In addition, the specimen might be teratological as it has a minute hind leg (the second is missing) with fused tarsomeres and only one claw (Fig. 2H). Subsequent collecting efforts resulted in only finding a single larval specimen.

We are not able to assign the Brachypsectra female and larva from Cyprus to any described species since only males are known in B. kadleci and B. jaechi sp. nov. The distribution of Brachypsectra species as well as the larger eyes in the female suggest its close relationship to $B$. jaechi sp. nov. from Turkey rather than to B. kadleci from Iran. The specimen from Cyprus differs from B. jaechi sp. nov. in having a lighter prosternum and mesoventrite, wider pronotal posterior angles with posterior carina very close to the lateral carina, and a shallower emarginate apex of the scutellum; however, we cannot exclude the possibility that this is only a result of sexual dimorphism. Until more material of both sexes and/or larvae for the Palaearctic species is available for study, we retain the population from Cyprus as Brachypsectra sp.

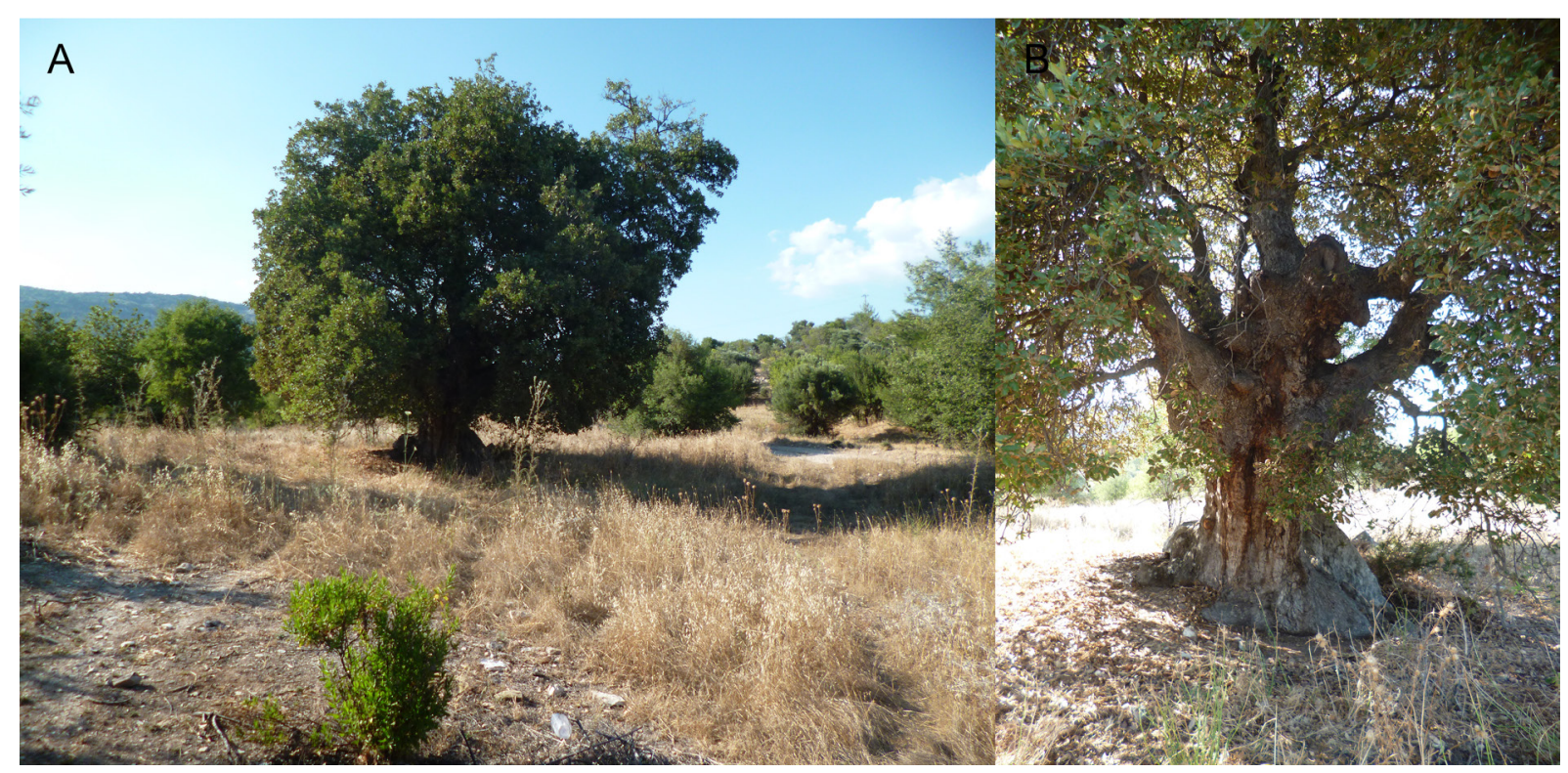

Fig. 4. A. Habitat of Brachypsectra sp. from Cyprus, Vretsia. B. Quercus infectoria Olivier. 
PETRZELKOVA I. et al., The genus Brachypsectra in the Palaearctic Region.

Key to species of Brachypsectra (modified from Costa et al. 2006)

\section{Adults (males)}

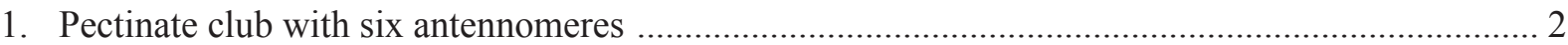

- Pectinate club with more than six antennomeres ........................................................................... 5

2. Eyes large; head between eyes less than 2.0 times as wide as eye width in dorsal view; pronotum slightly converging anteriorly

- Eyes smaller; head between eyes more than 3.0 times as wide as eye width in dorsal view; pronotum strongly converging anteriorly

3. Apical antennomere subtriangular with apical incision; pronotal posterior angles acute; punctation of elytra equal to that of pronotum; aedeagal median lobe with basal struts strongly diverging; paramere subparallel-sided, with lateral preapical acute projection (Singapore)

B. fuscula Blair, 1930

- Apical antennomere trapezoidal, broadening apically; pronotal posterior angles obtuse; punctation of elytra much finer than that of pronotum (Fig. 1A-D); aedeagal median lobe with basal struts U-shaped; paramere constricted apically, with lateral preapical and apical blunt projections (Fig. 2DE) (Iran; Fig. 3)

B. kadleci Hájek, 2010

4. Body unicoloured, yellowish brown; head broad; posterior pronotal carina concealing lateral carina in dorsal view; aedeagal median lobe subparallel-sided, apex broadly rounded; paramere with lateral preapical projection blunt (India)

B. lampyroides Blair, 1930

- Body bicoloured, testaceous, with elytra dark brown; head narrower; posterior pronotal carina separated from lateral carina in dorsal view (Fig. 1E-F); aedeagal median lobe gradually narrowed towards apex, apex subacute; paramere with lateral preapical projection subacute (Fig. 2F) (Turkey; Fig. 3)

B. jaechi sp. nov.

5. Distal inner angle of antennomeres 6-10 produced in an acute spine (amber, Dominican Republic) .....

B. moronei Branham in Costa et al., 2006

- Distal inner angle of antennomeres 6-10 not produced in an acute spine

6. Serration of antennal segments beginning on antennomere 5 ; antennomere 4 , if weakly serrate, much smaller than 5; sides of pronotum distinctly sinuate near base and posterior angles narrowly acute and laterally produced; paramere with lateral apical projection (Mexico, USA)

B. fulva LeConte, 1874

- Serration of antennal segments beginning on antennomere 4; antennomeres 4 and 5 equally serrate and similar in size; sides of pronotum more or less straight basally and posterior angles less acute and not laterally produced; paramere with lateral preapical projection (Dominican Republic)

B. vivafosile Woodruff, 2004

\section{Larvae}

1. Stemmata pedunculate; epicranial suture and gular sutures absent; mandible with retinaculum; anterior lobe of abdominal segment II undivided (Australia)

Brachypsectra sp.

- Stemmata not pedunculate; epicranial suture and gular sutures present; mandible without retinaculum; anterior lobe of abdominal segment II divided into lobules

2. Head about as wide as long; mandible slender; first segment of labial palp longer than second ..... 3

- Head wider than long; mandible stouter; first segment of labial palp as long as second ................. 4

3. Head subtrapezoidal; length of antenomere II 0.5 times head width; first segment of labial palp subparallel-sided (Mexico, USA)

B. fulva LeConte, 1874 
- Head suboval; length of antenomere II 0.7 times head width; first segment of labial palp expanded distally (amber, Dominican Republic)

B. moronei Branham in Costa et al., 2006

4. Head subrectangular; anterior lobe of abdominal segment II with three or more lobules (India)

B. lampyroides Blair, 1930

- Head subtrapezoidal (Fig. 2K-L); anterior lobe of abdominal segment II with two lobules (Fig. 2I-J) (Cyprus; Fig. 3) Brachypsectra sp. (this paper)

\section{Discussion}

Brachypsectra is usually considered a rare beetle lineage with only a scarce representation in collections (Costa et al. 2006). However, this might be caused by the cryptic life of the immature stages and short life span of adults (Fleenor \& Taber 1999; Costa et al. 2010). Indeed, the rarity of these beetles might have been overestimated since they may be quite abundant locally (see Fleenor \& Taber 1999). Additionally, considering the world distribution pattern of this genus (both present-day and historical; Costa et al. 2006; Klausnitzer 2009) and the recent findings of Brachypsectra in the Palaearctic Region (Fig. 3), we can expect that many more populations/species will be discovered in different zoogeographical regions in the near future.

\section{Acknowledgements}

We thank J. Hájek (NMPC), as well as M. Jäch and H. Schillhammer (NHMW) for the loan of material in their care, O. Merkl and T. Németh for their help during the stay of RK at the HNHM, I. Plonski for the help during the stay of RK at the NHMW and with finding some literature, R. Gabriš (Olomouc, Czech Republic) for the help with some photographs, and G. Oatley (University of Otago, New Zealand) for the proofreading. This study was supported by the internal grant of the Faculty of Science, Palacky University, Olomouc, and the EU-SYNTHESYS grants AT-TAF 3921 and HU-TAF 6125 (all to RK).

\section{References}

Blair K.G. 1930. Brachypsectra, Lec. - The solution of an entomological enigma. Transactions of the Royal Entomological Society of London 78: 45-50.

Costa C., Vanin S.A., Lawrence J.F., Ide S. \& Branham M. 2006. Review of the family Brachypsectridae (Coleoptera: Elateroidea). Annals of the Entomological Society of America 99: 409-432. http://dx.doi. org/10.1603/0013-8746(2006)99[409:ROTFBC]2.0.CO;2

Costa C., Vanin S.A., Lawrence J.F., Ide S. \& Branham M. 2010. Brachypsectridae Horn, 1881. In: Leschen R.A.B., Beutel R.G. \& Lawrence J.F. (vol. eds) Coleoptera, Beetles. Vol. 2: Morphology and Systematics (Elateroidea, Bostrichiformia, Cucujiformia partim): 47-54. Kristensen N.P. \& Beutel R.G. (series eds) Handbook of Zoology, Arthropoda: Insecta. Walter de Gruyter GmbH \& Co. KG, Berlin/ New York.

Crowson R.A. 1973. On a new superfamily Artematopoidea of polyphagan betles, with the definition of two new fossil genera from the Baltic amber. Journal of Natural History 7: 225-238. http://dx.doi. org/10.1080/00222937300770181

Fleenor S.B. \& Taber S.W. 1999. Review of Brachypsectra LeConte with a new record of the Texas beetle (B. fulva LeConte; Coleoptera: Brachypsectridae). Coleopterists Bulletin 53: 359-364.

Fleenor S.B. \& Taber S.W. 2000. Discovery of the female Texas beetle and notes on the ephemeral appearance of adults. Southwestern Entomologist 25: 303-305.

Hájek J. 2010. Brachypsectra kadleci sp. nov. from western Iran - the first Palaearctic member of the family Brachypsectridae (Insecta: Coleoptera: Elateriformia). Annales Zoologici 60: 29-33. http:// dx.doi.org/10.3161/000345410X499498 
PETRZELKOVA I. et al., The genus Brachypsectra in the Palaearctic Region.

Hoberlandt, L. 1981. Results of the Czechoslovak-Iranian entomological expeditions to Iran. Introduction to the second expedition 1973. Acta Entomologica Musei Nationalis Pragae 40: 5-32.

Hoberlandt, L. 1983. Results of the Czechoslovak-Iranian entomological expeditions to Iran. Introduction to the third expedition 1977. Acta Entomologica Musei Nationalis Pragae 41: 5-24.

Horn G.H. 1881. Notes on Elateridae, Cebrionidae, Rhipiceridae, and Dascyllidae. Transactions of the American Entomological Society 9: 76-90.

Klausnitzer B. 2009. Bemerkungen zu rezenten und fossilen Larven (Bernstein) der Gattung Brachypsectra LeConte (Coleoptera, Brachypsectridae). In: Kropf C. \& Horak P. (eds) Towards a Natural History of Arthropods and other Organisms. In Memoriam Konrad Thaler. Contributions to Natural History 12: 721-742.

Lawrence J.F. 1991. Brachypsectridae. In: Stehr F.W. (ed.) Immature Insects. Vol. 2: 421-422. Kendall Hunt, Dubuque, IA.

Lawrence J.F. \& Britton E.B. 1991. Coleoptera (Beetles). In: CSIRO (ed.) The Insects of Australia. A Textbook for Students and Research Workers. Vol. 2: 543-683. Melbourne University Press, Carlton, Victoria.

Lawrence, J.F. \& Newton, A.F. (1995). Families and subfamilies of Coleoptera (with selected genera, notes, references and data on family-group names). In: Pakaluk, J. \& Ślipiński, S.A. (eds) Biology, Phylogeny, and Classification of Coleoptera. Papers Celebrating the 80th Birthday of Roy A. Crowson. Volumes 1-2: 779-1083. Muzeum i Instytut Zoologii PAN, Warsaw.

Lawrence J.F., Ślipiński S.A., Seago A.E., Thayer M.K., Newton A.F. \& Marvaldi A.E. 2011. Phylogeny of the Coleoptera based on morphological characters of adults and larvae. Annales Zoologici 61: 1-217. http://dx.doi.org/10.3161/000345411X576725

LeConte J.L. 1874. Descriptions of new Coleoptera chiefly from the Pacific slope of North America. Transactions of the American Entomological Society 5: 43-72.

McKenna D.D., Wild A.L., Kanda K., Bellamy C.L., Beutel R.G., Caterino M.S., Farnum C.W., Hawks D.C., Ivie M.A., Jameson M.L., Leschen R.A.B., Marvaldi A.E., McHugh J.V., Newton A.F., Robertson J.A., Thayer M.K., Whiting M.F., Lawrence J.F., Ślipiński A., Maddison D.R. \& Farrell B.D. 2015. The beetle tree of life reveals that Coleoptera survived end-Permian mass extinction to diversify during the Cretaceous terrestrial revolution. Systematic Entomology 40: 835-880. http://dx.doi.org/10.1111/ syen. 12132

Neck R.W. 1993. Notes on habitats and rearing of Brachypsectra fulva LeConte (Coleoptera: Brachypsectridae). Coleopterists Bulletin 47: 291-292.

Woodruff R.E. 2004. A new species of the beetle genus Brachypsectra from the Dominican Republic, with fossil connections (Coleoptera: Brachypsectridae). Insecta Mundi 16: 161-170.

Young D.K. 2002. Brachypsectridae Bøving and Craighead 1931. In: Arnett Jr. R.H., Thomas M.C., Skelley P.E. \& Frank J.H. (eds) American Beetles. Vol. 2: 148-149. CRC Press, Boca Raton, FL.

Manuscript received: 4 April 2016

Manuscript accepted: 13 July 2016

Published on: 13 February 2017

Topic editor: Gavin Broad

Desk editor: Chloe Chester 
Printed versions of all papers are also deposited in the libraries of the institutes that are members of the EJT consortium: Muséum national d'Histoire naturelle, Paris, France; Botanic Garden Meise, Belgium; Royal Museum for Central Africa, Tervuren, Belgium; Natural History Museum, London, United Kingdom; Royal Belgian Institute of Natural Sciences, Brussels, Belgium; Natural History Museum of Denmark, Copenhagen, Denmark; Naturalis Biodiversity Center, Leiden, the Netherlands. 